\title{
RAIS: a real time strong-motion network in northern Italy
}

\author{
Paolo Augliera ${ }^{1,{ }^{\star}}$, Marco Massa $^{1}$, Ezio D'Alema ${ }^{2}$, Simone Marzorati $^{2}$ \\ ${ }^{1}$ Istituto Nazionale di Geofisica e Vulcanologia - INGV, Sezione Milano-Pavia, Milan, Italy \\ ${ }^{2}$ Istituto Nazionale di Geofisica e Vulcanologia - INGV, Centro Nazionale Terremoti, Italy
}

\section{Article history}

Received May 5, 2010; accepted November 11, 2010.

Subject classification:

Surveys, measurements and monitoring, Strong-motion network, Data-acquisition system, Data processing, Northern Italy.

\section{ABSTRACT}

When compared to more seismically active regions, damaging earthquakes occur only occasionally in the central part of northern Italy. Nevertheless, the lack of a dense strong-motion network in this area was highlighted by the occurrence of the November 24, 2004, $M_{L}$ 5.2, Salo earthquake. In 2006, the Istituto Nazionale di Geofisica e Vulcanologia (INGV) section of Milano-Pavia began the installation of new strong-motion stations in central-northern Italy. At present, the Strong-Motion Network of Northern Italy (RAIS; Rete Accelerometrica Italia Settentrionale) includes 22 stations with an average inter-distance of about $20 \mathrm{~km}$. All of the stations are equipped with Kinemetrics Episensor FBA ES-T sensors coupled with 24-bit digital recorders. Starting from 2009, 14 strong-motion stations have been sending data to the INGV acquisition center in Milan, in real time using TCP/IP over wi-fi links. Another eight stations still work in dial-up mode and send data through GSM modems. The real-time connections allow the use of strong-motion data recorded by RAIS for the generation of shake maps for Italy, the implementation of which represents one of the main tasks of the last agreement between INGV and the Italian Civil Protection Department. The RAIS data is stored directly at the INGV section of Milano-Pavia, which was realized using the MiniSEED format: the data management and exchange are carried out by the SeisComP package with the SeedLink protocol. Metadata dissemination is achieved through the website http://rais.mi.ingv.it, where the strong-motion parameters related to each recorded and processed waveform are made available.

\section{Introduction}

Strong-motion monitoring in Italy started in the early 1970 's, when a national strong-motion network was designed and installed by the Italian national energy and environment agency (ENEA; Agenzia nazionale per le nuove tecnologie, l'energia e lo sviluppo economico sostenibile) and the Italian electricity company ENEL SpA. Since 1997, the Italian National Strong-Motion Network (RAN; Rete Accelerometrica Nazionale) has been run by the Italian Civil Protection Department (DPC; Dipartimento della Protezione Civile). In spite of the relatively large number of RAN stations (at present, about 250 digital stations and 120 analog stations; http://itaca.mi.ingv.it), they do not provide homogeneous cover of the Italian territory. In particular, most of the stations are installed in areas characterized by high levels of seismicity, such as the central and southern Apennines, and the Friuli and Sicily regions. This problem became apparent after the occurrence of the November 24, 2004, $\mathrm{M}_{\mathrm{L}} 5.2$ $\left(M_{W}\right.$ 5.0) Salò earthquake [Augliera et al. 2006]. This event was one of the strongest earthquakes to strike the northern Italy regions over the last 30 years.

On the basis of the official data provided by the Lombardia regional authorities, this earthquake strongly affected about 70 municipalities close to the epicenter area. This resulted in damage to about 3,500 buildings and 300 churches, for an approximate damage evaluation of 200 million euros. In the epicenter area, only the Gavardo analog strong-motion station (GVD; see http: / /itaca.mi.ingv.it) was triggered during the mainshock (on the S-phase). The peak ground horizontal acceleration recorded at an epicenter distance of $14 \mathrm{~km}$ was $71 \mathrm{~cm} / \mathrm{s}^{2}$. Due to the lack of other strong-motion stations installed in the surroundings of the epicenter, no further data are available for distances less than $90 \mathrm{~km}$ from the epicenter.

With the aim to ascertain high-quality near-source recordings in the case of future earthquakes in northern Italy, in June 2006, the Istituto Nazionale di Geofisica e Vulcanologia section of Milano-Pavia (INGV-MI) started the installation of a dense strong-motion network in the area surrounding the November 24, 2004, epicenter: Rete Accelerometrica Italia Settentrionale (RAIS; Strong-Motion Network of Northern Italy; http:/ / rais.mi.ingvit) (Figure 1).

Even if central-northern Italy is a region that is characterized by low seismicity (in terms of both energy release and occurrence of events), the importance and necessity of strong-motion monitoring in this areas has been demonstrated by the occurrence of some relevant historical earthquakes (Figure 2, bottom panel), such as the $1117 \mathrm{M}_{\mathrm{W}}$ 6.49 Verona earthquake, the $1222 \mathrm{M}_{\mathrm{W}} 6.05$ Brescia earthquake, the $1695 \mathrm{M}_{\mathrm{w}} 6.61$ Asolo earthquake and the more recent 1901 


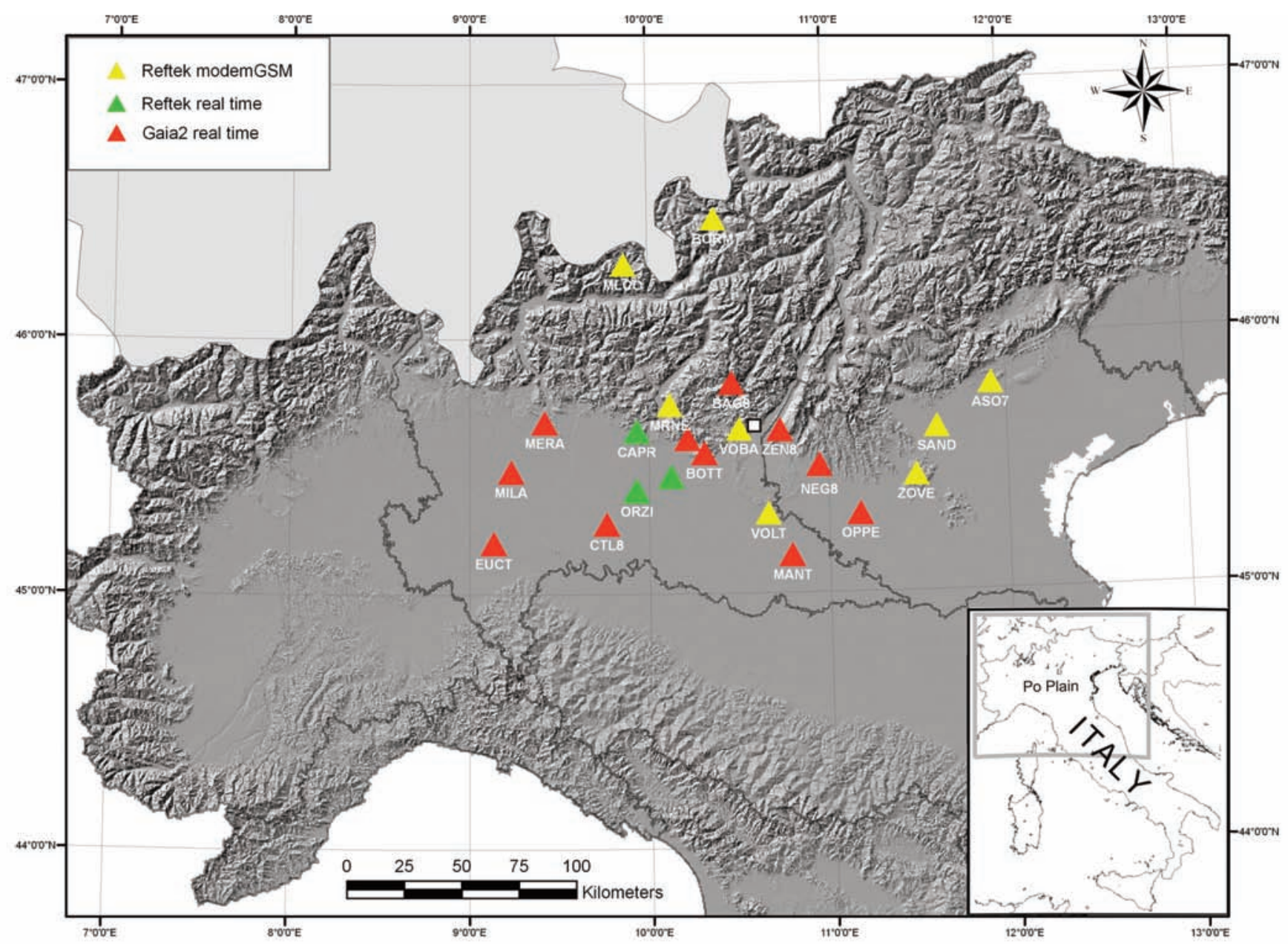

Figure 1. RAIS strong-motion network. Different colors indicate stations characterized by different recording systems or different data-transmission types (as indicated). White square, epicenter of the November 24, 2004, $\mathrm{M}_{\mathrm{L}}$ 5.2, Salò earthquake.

$\mathrm{M}_{\mathrm{W}} 5.67$ Salò earthquake [Gruppo di lavoro CPTI 2004].

At present, after four years of recordings, the data stored at the acquisition center in Milan has allowed us to construct a high-quality dataset (Figure 2, top panel) composed of 103 events (about 2,000 three-components waveforms) with $\mathrm{M}_{\mathrm{L}}$ ranging from 0.7 to 5.1 (the December 23, 2008, Parma earthquake).

This study is focused on the RAIS technological upgrade that has been performed in the last two years. The first phase of installations, as the main features of the first-generation RAIS (mainly based on a dial-up transmission system) and its detection capability, were described in a previous study [Augliera et al. 2009]. In the present study, the latest developments and the present configuration of the network are presented, with particular attention to site selection, acquisition system and data transmission. The final section of this study focuses on data processing and real-time dissemination, with the aim, in particular, to improve the generation of shake maps for events that occur in northern Italy.

\section{Site selection and characterization}

RAIS arose in the framework of a 2004-2006 INGV-DPC agreement. The first installations were founded through the project «Stazioni Accelerometriche» («Strong-Motion Stations»; http://accel.mi.ingv.it/progettoaccel/), while further developments were carried out through the last INGV-DPC S3 project «Fast evaluation of the parameters and effects of strong earthquakes in Italy and in Mediterranean areas». At the beginning, two of the main goals of the Stazioni Accelerometriche project were to improve earthquake detection in the area of central-northern Italy, and to ascertain a tool for strong-motion monitoring that can provide high-quality records in the case of strong events. The first phase of the project concerned the selection of sites suitable for seismic installations. In this way, three main aspects were considered: the locations of the seismic stations managed by other organizations (Figure 3), to avoid too high or too low a density of stations (both weak and strongmotion) in any particular area; the location of instrumental seismicity recorded in the region under study from 1981 (http:/ / bollettinosismico.rm.ingv.it/ and http:/ / csi.rm.ingv. it/); and the municipality of the area characterized by the greatest seismic hazard (http:/ / esse1.mi.ingv.it/) [Gruppo di Lavoro MPS 2004], expressed in terms of the maximum peak ground horizontal acceleration, with a $10 \%$ probability of being exceeded in the next 50 years (return period, 475 years). 


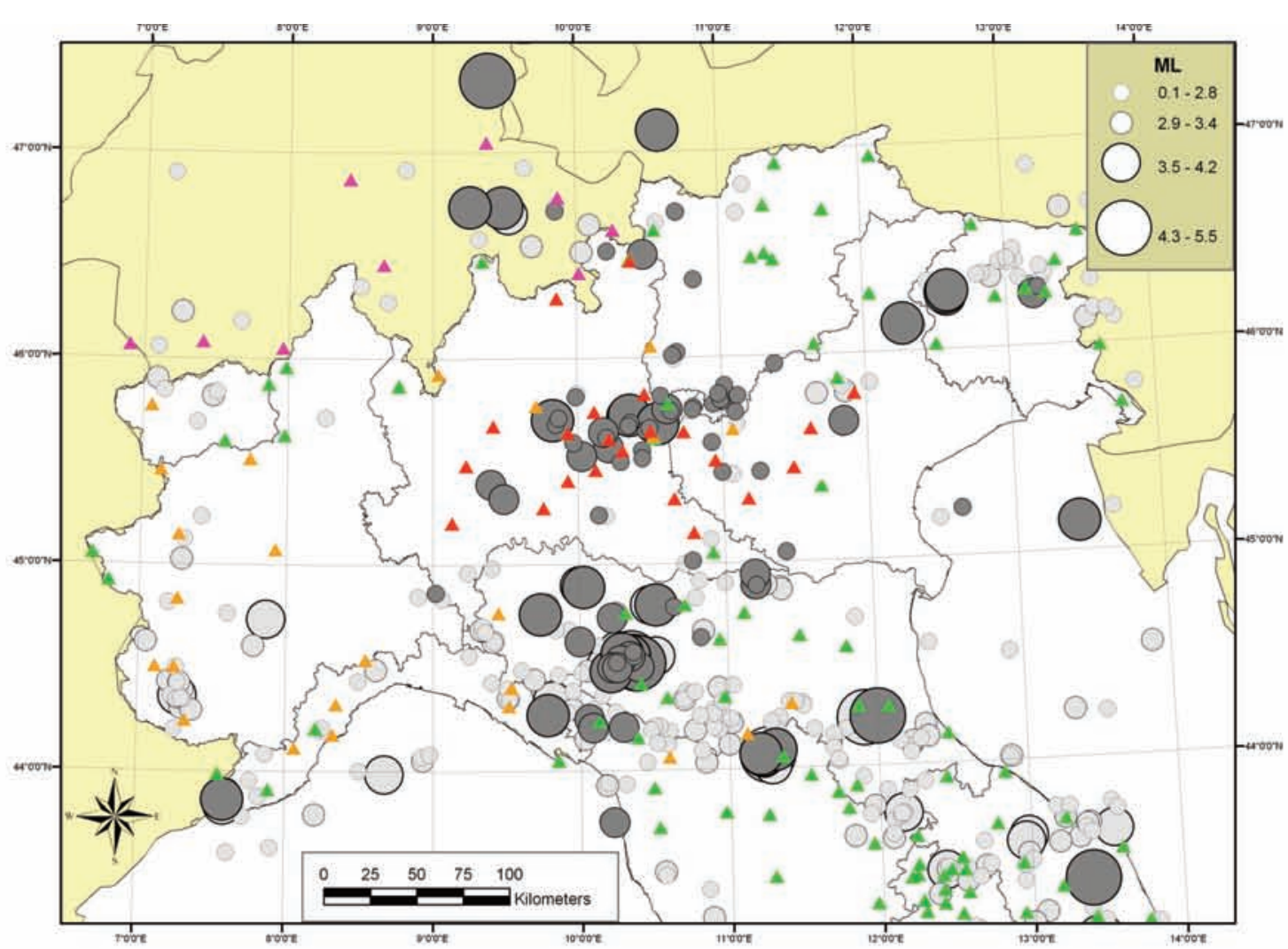

46

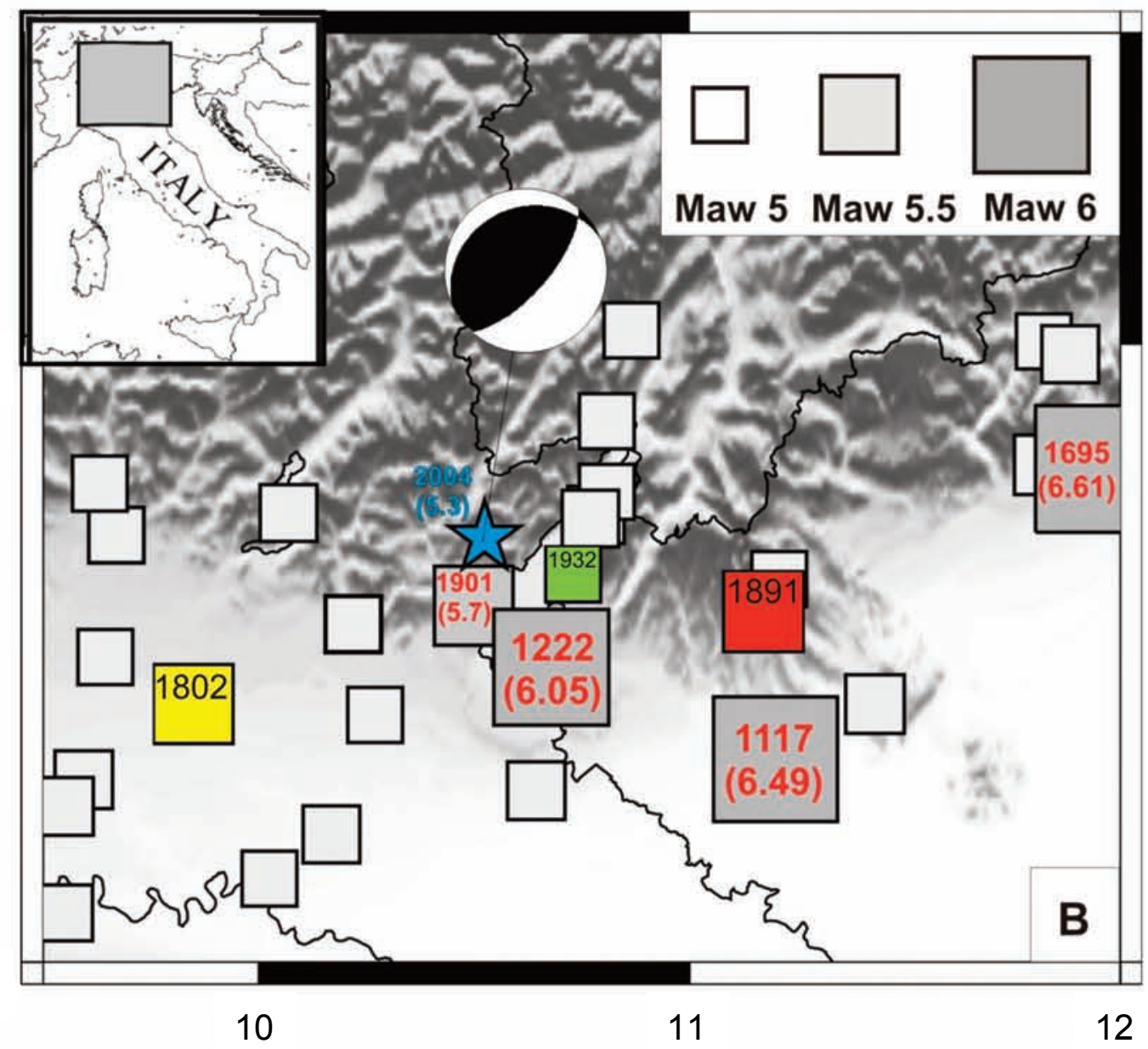

Figure 2. Top panel: events recorded by RAIS from June 2006 to June 2010 (dark grey circles) and background seismicity in northern Italy (light grey circles). Epicenter coordinates are derived from the official INGV instrumental bulletin (http:/ / bollettinosismico.rm.ingv.it/). Red triangles, RAIS strong-motion stations. Bottom panel: historical seismicity of the area under study (from CPTI04) [Gruppo di Lavoro CPTI 2004]. Blue star, epicenter of the November 24, 2004, $\mathrm{M}_{\mathrm{L}}$ 5.2, Salò earthquake. 


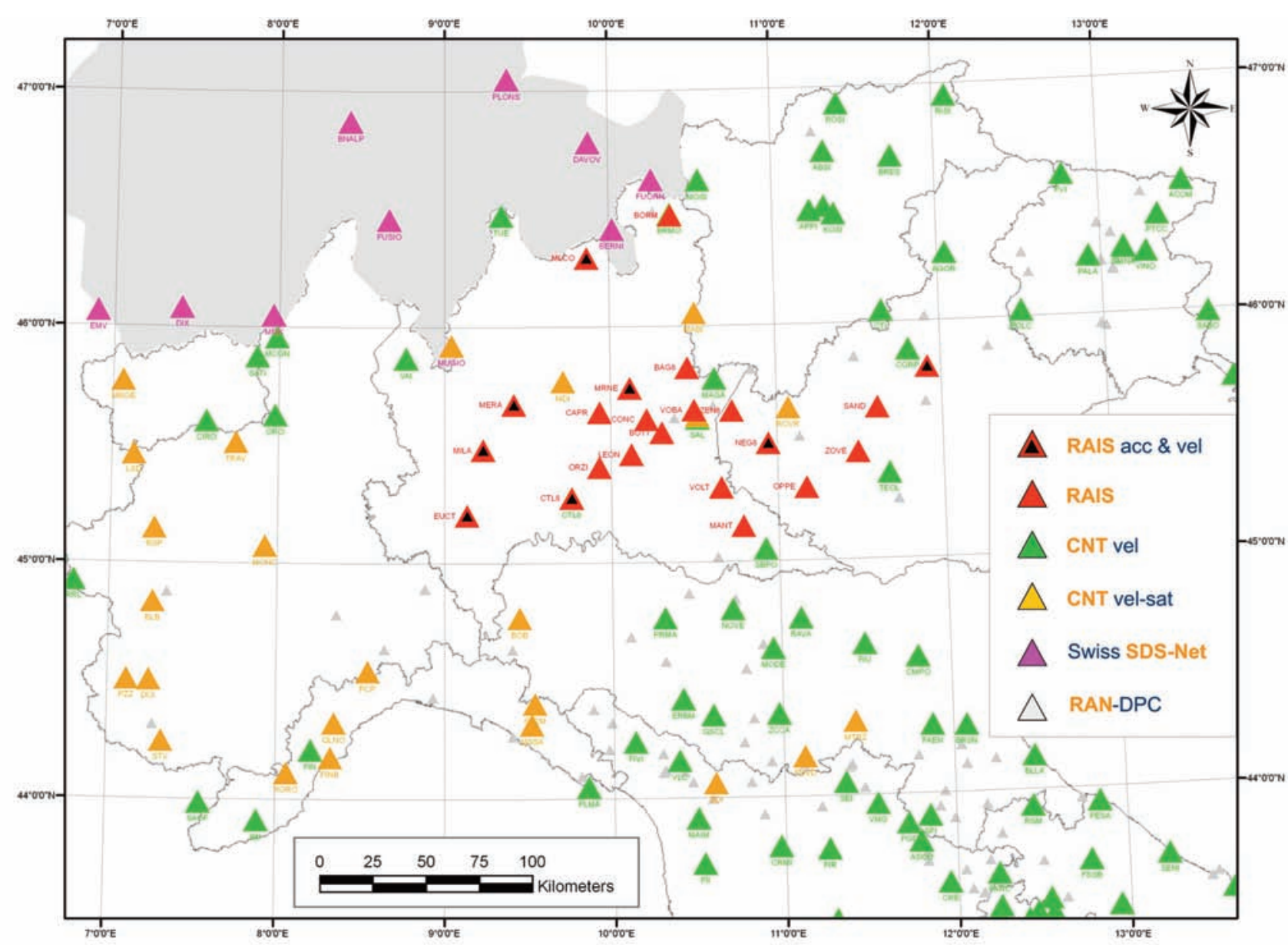

Figure 3. RAIS and national seismic networks in northern Italy and its surroundings. Red triangles, RAIS stations (http:// rais.mi.ingvit); black triangles inside red triangles, site equipped with both weak and strong-motion sensors; green triangles, velocimetric stations managed by the National Earthquake Center of INGV (CNT, http: / / cnt.rm.ingv.it/); yellow triangles, INGV-CNT satellite velocimetric stations; gray triangles, RAN strong-motion stations managed by Italian Civil Protection (DPC, http:/ / www.protezionecivile.it/); violet triangles, SDS-Net velocimetric stations (http:/ / www.seismo.ethz.ch/).

Figure 3 shows only the RAIS and the national network, but other local and regional networks that have operated in this area were considered; e.g. the Friuli-Venezia Giulia Accelerometric Network (RAF), the short-period seismometric regional networks of Friuli-Venezia Giulia (RSFVG) and of Veneto (RSV) managed by the Centro di Ricerche Sismologiche of the Istituto Nazionale di Oceanografia e di Geofisica Sperimentale (OGS), and the Regional Seismic Network of Northwestern Italy (RSNI; managed by Dipartimento per lo Studio del Territorio e delle sue Risorse, Genoa University). For each site considered, the final selection generally represented a compromise between the network geometry, which depends on the monitoring purposes, and the characteristics that a given site has in terms of being suitable for an installation.

Considering the high degree of urbanization and industrialization in the area considered, all of the installations were preceded by microtremor analysis [Nakamura 1989]. Taking into account that it is difficult to achieve a low level of noise in this area [Peterson 1993], the selection was carried out in particular with the aim of avoiding any very unfavorable situations.
For each site, the quick horizontal-to-vertical spectral ratio (HVSR) and additional probability density functions [McNamara and Buland 2004] are computed following the procedures presented by Marzorati and Bindi [2006]. For the processing of the seismic noise, time series with durations of at least $30 \mathrm{~min}$ are considered, recorded with a broad-band sensor (sampling frequency, $100 \mathrm{~Hz}$ ). These time series are divided into segments of $60 \mathrm{~s}$ with an overlap of $75 \%$, to reduce the variance in the power spectral density (PSD) computations. For each window of noise, the mean and the linear trends are removed, and a digital Butterworth filter is applied, in the frequency range $0.1 \mathrm{~Hz}$ to $25 \mathrm{~Hz}$.

At present, all of the sites where a RAIS station is installed are characterized from both the geological (http:/ / rais.mi.ingvit; link caratterizzazione siti) and geophysical points of view. For the geology, all of the information has come from 1:25,000 geological maps provided by the Lombardia region [CARG project 2003] or from 1:100,000 Italian geological maps [Società Geologica Italiana 1984]. From a geophysical point of view, for each site, an averaged HVSR is available considering the earthquake recordings from June 2006.

For each recorded waveform, an automatic procedure 
allows the step-by-step updating of the present averaged amplification function calculated for a single site. The processing of the recorded strong-motion data (sampling frequency, $100 \mathrm{~Hz}$ ) includes the following steps: removal of the mean and the linear trends; $5 \%$ cosine tapering; and application of an acasual four-pole Butterworth band-pass filter between $0.2 \mathrm{~Hz}$ and $25 \mathrm{~Hz}$. For each event, the Fourier spectra are computed considering different time windows (5 $\mathrm{s}$ and $10 \mathrm{~s}$, starting $0.5 \mathrm{~s}$ before the $\mathrm{S}$-phase onset).

To investigate the differences between the differently polarized horizontal components, directional spectral ratios are obtained by applying different rotation angles. In particular, for computing the directional spectral ratios, the NS and EW components are rotated clock-wise from the North by between $0^{\circ}$ and $175^{\circ}$, in angular steps of $5^{\circ}$. This provides for the computation of 36 rotated components, which are representative of 36 directions of horizontal ground shaking. A summary of the products available at each site is given in Figure 4 for the Vobarno station (VOBA in Table 1).

Finally, taking into account both the geological and
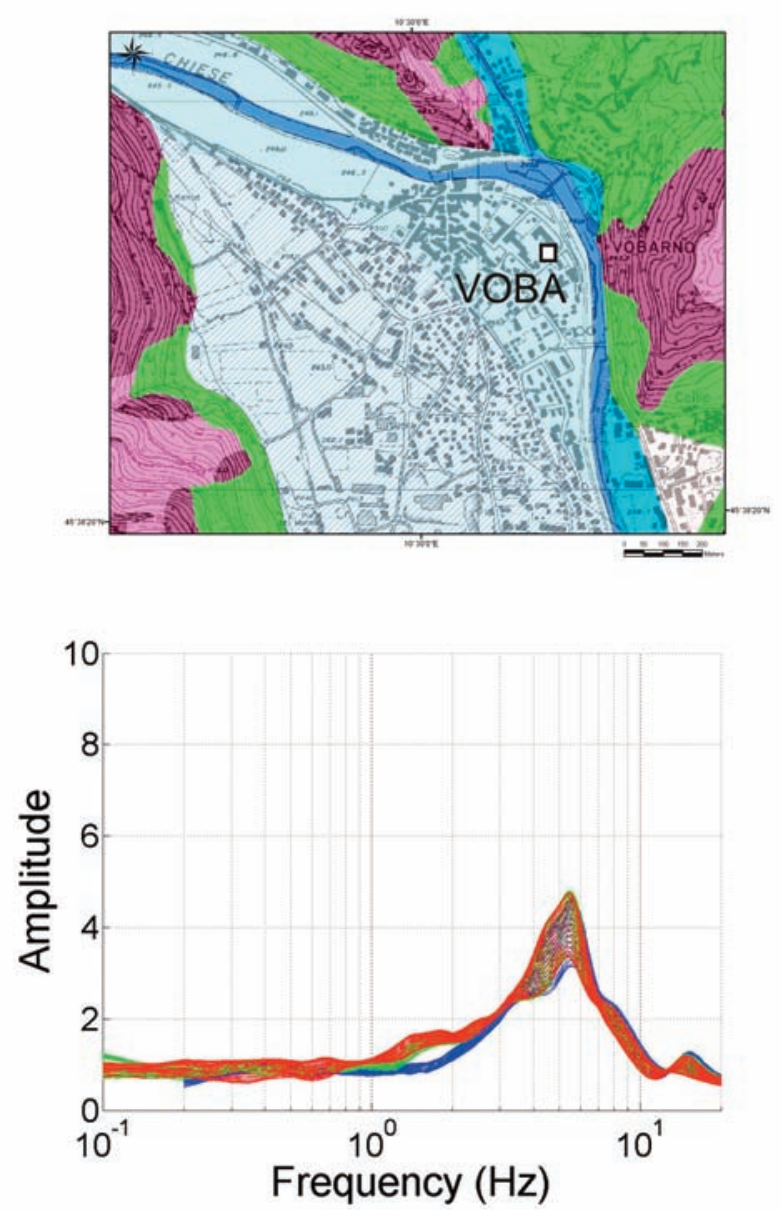

geophysical indications, all of the stations are classified following the provision of the Italian seismic building code [NTC 2008].

\section{Instrumentation and installation}

At present, RAIS is composed of 22 stations (Table 1): the strong-motion sensors are Episensor model FBA ES-T force balance accelerometer sensors (http / / www.kinemetrics. com), which are characterized by a dynamic range of $155 \mathrm{~dB}$. Generally, the full-scale is set to $\pm 2.0 \mathrm{~g}$. Figure 5 shows the typical arrangements of the installations. At each site, the accelerometer is housed in an ad-hoc built concrete basement, to which it is anchored (Figure 5, top right). Close to the concrete basement there is a plastic box with the dimensions of about $100 \mathrm{~cm}$ length, $80 \mathrm{~cm}$ width and $50 \mathrm{~cm}$ height. This box contains the digital recorder (GAIA-2 recorder in Figure 5, bottom left), a router for data transmission (TCP/IP protocol), and a stabilized power supply connected to a $12 \mathrm{v}$ battery, to avoid a possible loss of electricity (Figure 5, bottom left).

The time synchronization of the signals recorded is
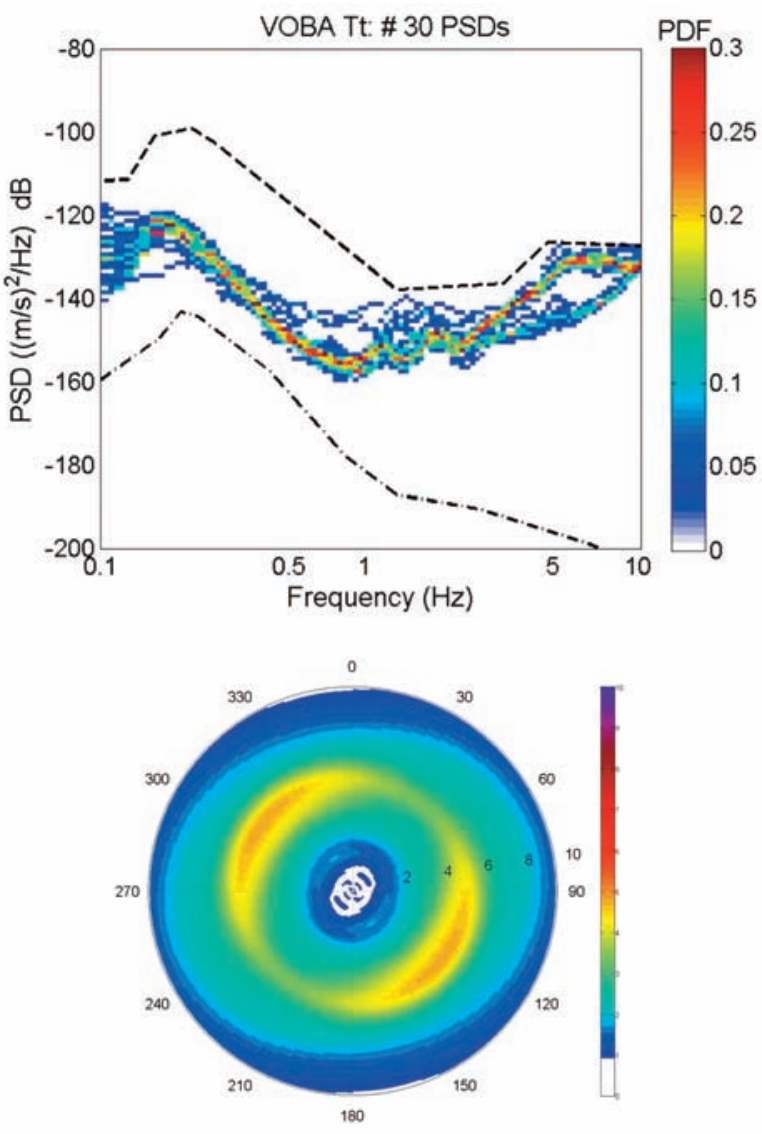

Figure 4. Site characterization of VOBA station (NTC08 B lithological class, see also Table 1). Top left: geological map (1:25,000 scale). Top right: probability density function of power spectral density performed on seismic noise. Bottom left: horizontal-to-vertical spectral ratio performed considering recorded earthquakes (different colors indicate different portions of the S-phase). Bottom right: frequency-azimuth polar plot (third dimension indicates value of amplification function). 


\begin{tabular}{|c|c|c|c|c|c|c|c|c|c|c|c|}
\hline \multicolumn{2}{|c|}{ Station (site class) } & \multirow{2}{*}{$\begin{array}{c}\text { Site } \\
\text { Milano }\end{array}$} & \multirow{2}{*}{$\begin{array}{l}\text { Province } \\
\text { Milano }\end{array}$} & \multirow{2}{*}{$\begin{array}{c}\begin{array}{c}\text { Latitude } \\
(\mathbf{N})\end{array} \\
45.480\end{array}$} & \multirow{2}{*}{$\begin{array}{c}\text { Longitude } \\
\text { (E) }\end{array}$} & \multirow{2}{*}{$\begin{array}{c}\begin{array}{c}\text { Elevation } \\
(\mathrm{m})\end{array} \\
125\end{array}$} & \multirow{2}{*}{$\begin{array}{c}\text { Sensor } \\
\text { Episensor }\end{array}$} & \multirow{2}{*}{$\begin{array}{c}\begin{array}{c}\text { Full-scale } \\
(\mathrm{g})\end{array} \\
(1.0)\end{array}$} & \multirow{2}{*}{$\begin{array}{c}\begin{array}{c}\text { Rec. } \\
\text { System }\end{array} \\
\text { Gaia2 }\end{array}$} & \multirow{2}{*}{$\begin{array}{c}\text { Transmission } \\
\text { Real Time }\end{array}$} & \multirow{2}{*}{$\begin{array}{c}\text { Since } \\
01.06 .06\end{array}$} \\
\hline MILA & C & & & & & & & & & & \\
\hline MERA & B & Merate & Lecco & 45.672 & 9.418 & 350 & Episensor & $(2.0)$ & Gaia2 & Real Time & 25.10 .05 \\
\hline EUCT & $\mathrm{C}$ & Pavia & Pavia & 45.202 & 9.134 & 82 & Episensor & $(2.0)$ & Gaia2 & Real Time & 26.06 .06 \\
\hline CTL8 & C & Castelleone & Cremona & 45.275 & 9.762 & 66 & Episensor & $(2.0)$ & Gaia2 & Real Time & 22.07.09 \\
\hline BAG8 & A & Bagolino & Brescia & 45.822 & 10.466 & 807 & Episensor & $(2.0)$ & Gaia2 & Real Time & 15.06 .06 \\
\hline CONC & B & Concesio & Brescia & 45.606 & 10.217 & 126 & Episensor & $(0.25)$ & Gaia2 & Real Time & 03.05 .06 \\
\hline OPPE & C & Oppeano & Verona & 45.308 & 11.172 & 20 & Episensor & $(2.0)$ & Gaia2 & Real Time & 24.09 .09 \\
\hline BOTT & A & Botticino & Brescia & 45.549 & 10.309 & 200 & Episensor & $(2.0)$ & Gaia2 & Real Time & 27.10 .09 \\
\hline ZEN8 & A & San Zeno Montagna & Verona & 45.637 & 10.731 & 596 & Episensor & $(2.0)$ & Gaia2 & Real Time & 30.06 .06 \\
\hline MANT & C & Mantova & Mantova & 45.149 & 10.789 & 36 & Episensor & $(2.0)$ & Gaia2 & Real Time & 29.07.09 \\
\hline CAPR & B & Capriolo & Brescia & 45.637 & 9.934 & 215 & Episensor & $(2.0)$ & Reftek & Real Time & 31.05 .06 \\
\hline LEON & C & Capriano del Colle & Brescia & 45.458 & 10.123 & 92 & Episensor & $(2.0)$ & Reftek & Real Time & 18.07.07 \\
\hline ORZI & C & Orzinuovi & Brescia & 45.405 & 9.930 & 83 & Episensor & $(2.0)$ & Reftek & Real Time & 24.04 .08 \\
\hline VOBA & B & Vobarno & Brescia & 45.642 & 10.504 & 292 & Episensor & $(2.0)$ & Reftek & Modem GSM & 28.06 .06 \\
\hline ASO7 & A & Asolo & Treviso & 45.804 & 11.918 & 221 & Episensor & $(2.0)$ & Reftek & Modem GSM & 03.08 .06 \\
\hline BORM & A & Bormio & Sondrio & 46.469 & 10.376 & 1235 & Episensor & $(2.0)$ & Reftek & Modem GSM & 29.11 .06 \\
\hline MLCO & A & Chiesa Val Malenco & Sondrio & 46.291 & 9.863 & 2030 & Episensor & $(2.0)$ & Reftek & Modem GSM & 30.11 .06 \\
\hline ZOVE & A & Zovencedo & Vicenza & 45.453 & 11.487 & 376 & Episensor & $(2.0)$ & Reftek & Modem GSM & 28.06 .07 \\
\hline MRNE & A & Marone & Brescia & 45.739 & 10.117 & 600 & Episensor & $(2.0)$ & Reftek & Modem GSM & 10.07.07 \\
\hline VOLT & C & Volta Mantovana & Mantova & 45.313 & 10.660 & 107 & Episensor & $(2.0)$ & Reftek & Modem GSM & 09.11 .07 \\
\hline SAND & C & Sandrigo & Vicenza & 45.640 & 11.609 & 51 & Episensor & $(2.0)$ & Reftek & Modem GSM & 19.12.07 \\
\hline NEG8 & A & Negrar & Verona & 45.497 & 10.948 & 167 & Episensor & (2.0) & Gaia2 & Real Time & 29.06 .10 \\
\hline
\end{tabular}

Table 1. Main features of the RAIS stations.

ascertained via a GPS antenna installed near the station. At present, the network is characterized by two different types of digital recorders: 11 strong-motion sensors coupled to 24bit Reftek 130-01 digital recorders (http: / / www.reftek.com); with the other 11 sensors coupled to 24-bit GAIA-2 [Rao et al. 2010]. This type of digital recorder was directly designed and produced by the laboratory of the INGV-CNT (http: / / cnt.rm.ingv.it). At present, all of the stations record signals in continuous mode, with a sampling frequency of $100 \mathrm{~Hz}$.

\section{Acquisition system and data transmission: a brief history, and the present}

From June 2006 to the end of 2008, the Episensors installed were equipped with 20-bit Lennartz Mars88 Modem Control (http://www.lennartz-electronic.de/) or 24-bit Reftek 130 digital recorders. In both cases, the remote stations transmitted the data to the INGV-MI acquisition center using Global System for Mobile Communications (GSM) modems [D'Alema and Marzorati 2003, D'Alema 2007]. The GSM data transmission did not allow real-time determination of the engineering parameters, which actually represents one of the main goals for a strong-motion network.

In this initial period, the GSM data transmission system represented a relevant technological limitation, which forced the on-line data dissemination to have a time delay of the order of hours. In the framework of the recent 2007-2009 INGV-DCP S3 project, great efforts have been made to replace the highest possible number of GSM stations with a system that can record data in continuous mode and at the same time transmit the data in real time. This important evolution of the network started at the beginning of 2009, and it has led to the replacement of the Mars88 Modem Control digital recorders (without TCP/IP support, and thereby not suitable to transmit data in continuous mode) with 24-bit digital recorders. At the same time, the present phase (still in progress) has led the replacement of the GSM technology with TCP-IP connections.

At present, 14 stations of the total of 22 are connected to the acquisition center in Milan in real time. Eleven of these 14 stations are now equipped with GAIA2 digital recorders, while three others are equipped with Reftek-130 digital recorders. The other eight stations are still dial-up stations, 
and they send data via GSM modems. For the management of the real-time stations, the SeedLink protocol has been adopted. The format of the recorded data (previously recorded both in binary Reftek and Lennartz format, and then stored in sac format) has been upgraded, to introduce the MiniSEED format. We use the SeedLink system for realtime communication using TCP/IP protocols, and a SeisComP platform [Hanka et al 2000] for monitor plotting and disk recording.

For data acquisition, a procedure for events detection was developed. The locations are provided by the Italian National Earthquake Center (INGV-CNT, http:/ / cnt.rm.ingv. it). In our case, a new event location represents a warning for RAIS data acquisition, and consequently the trigger for the fully automatic system. In particular, every $5 \mathrm{~min}$ the file of event locations (revised by the seismologist who is in charge of the seismic surveillance activities in Rome) are automatically downloaded.

Every time a new event occurs, the theoretical spectral amplitude of the earthquake is compared (in a fixed frequency band) with the average noise levels for each station of the network. The synthetic spectrum is computed by considering the omega-square source model [Brune 1970], and the source spectrum is propagated to each station by considering the $1 / \mathrm{R}$ geometrical spreading term. In this case, some bias (however negligible, considering our scope) can be introduced by the non-correspondence between moment (on which the theoretical scheme is based) and local (recorded) magnitude. The procedure is, however, conservative [Augliera et al. 2009]. At the end of the procedure, if the theoretical signal-to-noise ratio exceeds a fixed threshold for at least three stations, the INGV-CNT event-ID is stored and the procedure for the automatic download of the RAIS data starts. The event-ID represents the necessary information to merge the data previously processed by different seismic networks in a consistent way, when sent to the common server of INGV-CNT.

At the end of the process, the RAIS waveforms are available at our acquisition center and are ready to be processed by the automatic system. A summary of the procedure is shown in the flow-chart in Figure 6.

\section{Data processing and dissemination}

After the acquisition system, the RAIS data are available at the workstation of the acquisition center in Milan. The last step is represented by the data processing and dissemination. The analyses of the recorded data are automatically carried out using a series of codes that were expressly developed both in the Fortran77 and C languages, and in bash-shell. Each strong-motion waveform is processed using a standard procedure, as described by Massa et al. [2009], which includes baseline correction (performed by least square regression), mean removal considering the
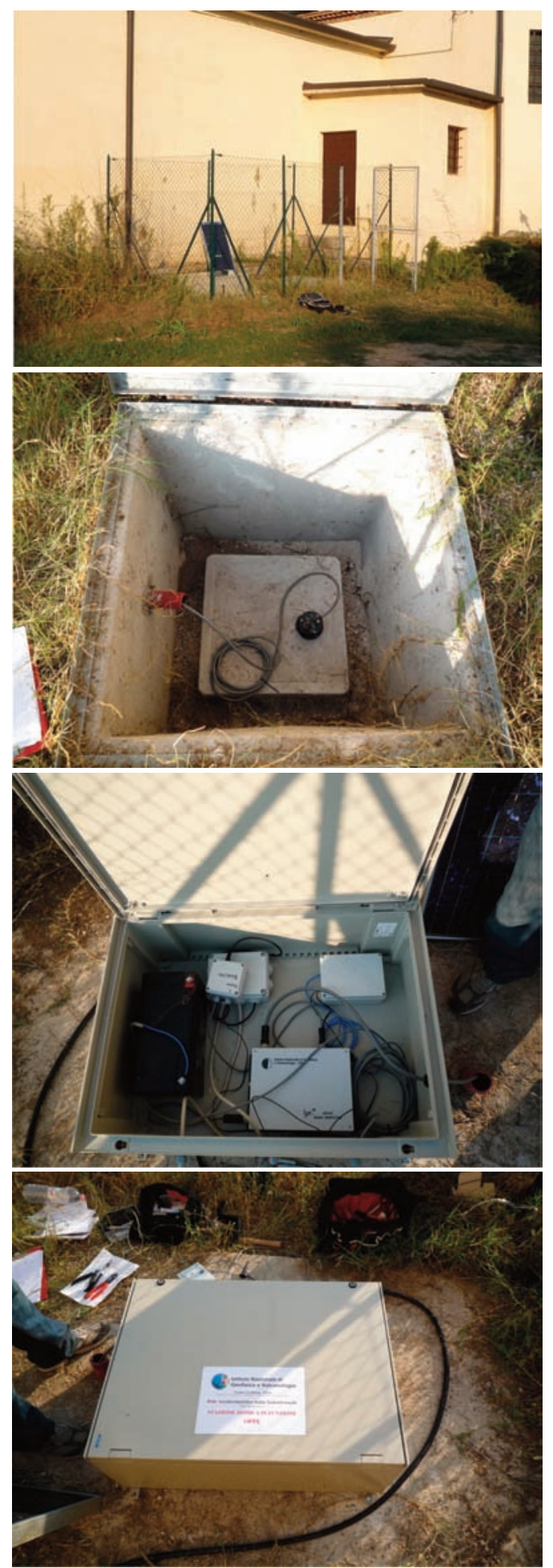

Figure 5. Typical installation arrangements. From top to bottom: external view; concrete basement where strong-motion sensor is anchored; plastic box that includes the recording system (open); plastic box (closed).

whole signal, application of a cosine-taper function (usually $5 \%$ ), and filtering performed by an acasual 4th-order Butterworth digital filter $(0.2-30 \mathrm{~Hz})$.

For all of the processed waveforms, the peak ground acceleration (PGA) and acceleration response spectra (5\% damped) for periods up to $4 \mathrm{~s}$ are calculated. Moreover, the automatic system also provides pseudo-velocity response spectra, displacement response spectra, Arias intensities 


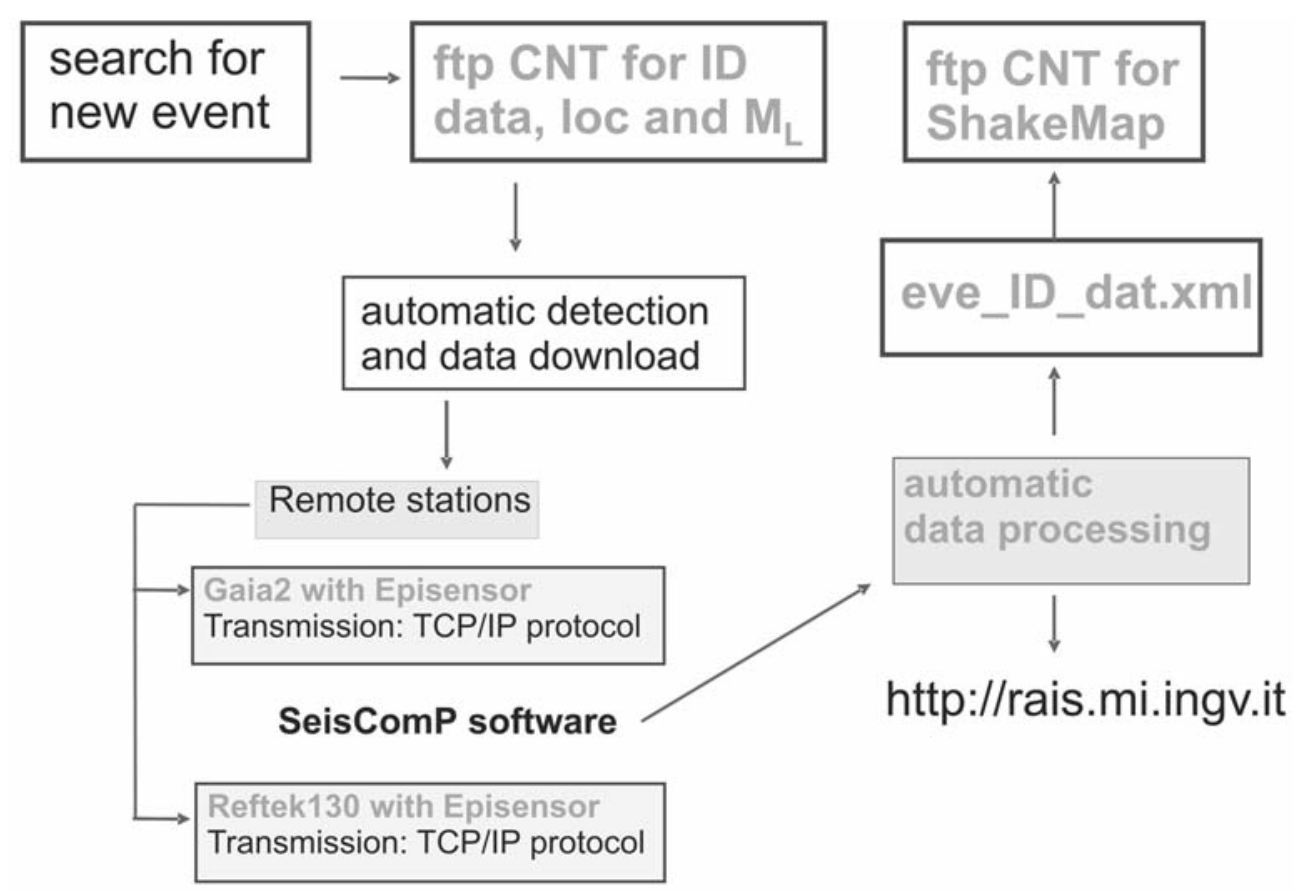

Figure 6. Flow chart representing the acquisition system and data transmission for the RAIS network.

[Arias 1970] and Housner intensities [Housner 1952]. Finally, after the integration of the acceleration time series, the peak ground velocity is also determined. For the site response, as discussed above, for each recorded event at each site, the earthquake HVSR is calculated, considering both $5 \mathrm{~s}$ and 10 $s$ of the $S$ phase. The metadata are collected on the website of the RAIS network (http: / / rais.mi.ingv.it), while all of the waveforms related to each event with a $M_{L} \geq 2.5$ are included in the Italian Accelerometric Archive (ITACA) and are downloadable from its website (http://itaca.mi.ingv.it). Moreover, since 2009, for each event with a $M_{L} \geq 3.0$, the PGA, peak ground velocity and acceleration response spectra values (for periods of $0.3 \mathrm{~s}, 1.0 \mathrm{~s}$ and $3.0 \mathrm{~s}$ ) are sent to the INGV-CNT acquisition center, where they are merged together with all of the available strong-motion and velocimetric data, to improve the calculations with ShakeMap (http: / / earthquake.rm.ingv.it/shakemap/shake/) for these events that occur in northern Italy.

\section{The 2006-2010 RAIS dataset}

In the period from June 2006 to June 2010, the RAIS network allowed us to collect a relevant dataset, at least in terms of the number of earthquakes for this area with low seismicity. Over this period, 103 events (total of about 2,000 three-component waveforms) with $\mathrm{M}_{\mathrm{L}}$ ranging from 0.7 to 5.1 were recorded in the epicenter distance range from $5 \mathrm{~km}$ to $250 \mathrm{~km}$ (Figure 7). For the magnitudes, the most relevant earthquake was recorded on December 23, 2008, at 15.23 UTC ( $\mathrm{M}_{\mathrm{L}}$ 5.1; Parma earthquake; http: / / rais.mi.ingv.it/ statiche/PARMA-2008/HTML/main.html).

For the acceleration, the earthquake that produced the highest recorded peak was the July 14, 2008, $\mathrm{M}_{\mathrm{L}} 3.5$ Salò event. This relatively weak earthquake produced a horizontal acceleration peak of $33 \mathrm{~cm} / \mathrm{s}^{2}$ at Vobarno station (VOBA; see Table 1), which was located about $5 \mathrm{~km}$ West of the epicenter.

In general, as shown in Figure 7 (top left), the highest number of recorded events were in the magnitude range $M_{L} 2.5$ to 4.0. In this interval, the records homogeneously cover the hypocenter distance range from $10 \mathrm{~km}$ to $200 \mathrm{~km}$. For magnitudes between $\mathrm{M}_{\mathrm{L}} 0.7$ (minimum recorded) and 2.5 , the hypocenter distances range from $50 \mathrm{~km}$ to $75 \mathrm{~km}$ (Figure 7 , bottom left). The same examination of the data can be made if the right panels of Figure 7 are considered. In particular, the bottom right panel shows PGA versus hypocenter distance for events with $M_{L} \geq 3.0$, where anomalous peaks for hypocenter distances close to around $100 \mathrm{~km}$ can be seen. This phenomenon is due to the not-sonegligible contribution of the Moho reflection in the areas located in the eastern region of the Po Plain, as demonstrated by Castro et al. [2008] and Bragato et al. [2009]. However, it is also not possible to exclude the contribution of local site effects for stations located in B and C lithological classes (see Table 1), as described in the Italian seismic building codes [NTC 2008].

To strengthen the benefit of the RAIS network for strong-motion monitoring of the area under study, in Augliera et al. [2009] a theoretical example was considered around some of the strongest historical events [Gruppo di Lavoro CPTI 2004] that have occurred in the northern Italy regions (Figure 2, bottom panel). In the case of a "re-occurrence", the May 12, 1802, $\mathrm{M}_{\mathrm{W}} 5.67$ Oglio Valley earthquake (maximum macroseismic intensity, $\mathrm{I}_{\max }$, of MercalliCancani-Sieberg (MCS) VIII-IX; Figure 2, bottom panel, 
yellow square) would currently be recorded by five strongmotion stations (four belonging to RAIS) in the first $30 \mathrm{~km}$. Similarly, the June 7, 1891, $\mathrm{M}_{\mathrm{W}} 5.71$ Illasi Valley earthquake ( $\mathrm{I}_{\max }$, MCS IX; Figure 2, bottom panel, red square) and the February 19, 1932, $\mathrm{M}_{\mathrm{W}} 5.01$ Mount Baldo earthquake ( $\mathrm{I}_{\max }$, MCS VIII; Figure 2, bottom panel, green square) would have produced non-saturated data at seven stations (six belonging to RAIS) and 12 stations (seven belonging to RAIS) for epicenter distances less than $30 \mathrm{~km}$, respectively (for more details, see Augliera et al. [2009]). In particular, considering the hypothetical doublet of the November 24, 2004, $\mathrm{M}_{\mathrm{L}} 5.2$ Salò event (Figure 2, bottom panel, blue star), it is possible that a similar event would now be recorded by 11 strongmotion stations (six belonging to RAIS) in the first $30 \mathrm{~km}$.

\section{ShakeMap implementation at RAIS}

Shake maps are very useful tools in the first minutes to hours after an earthquake has occurred, but their relevance progressively decreases as information about the actual damage becomes available. For this reason it is fundamental
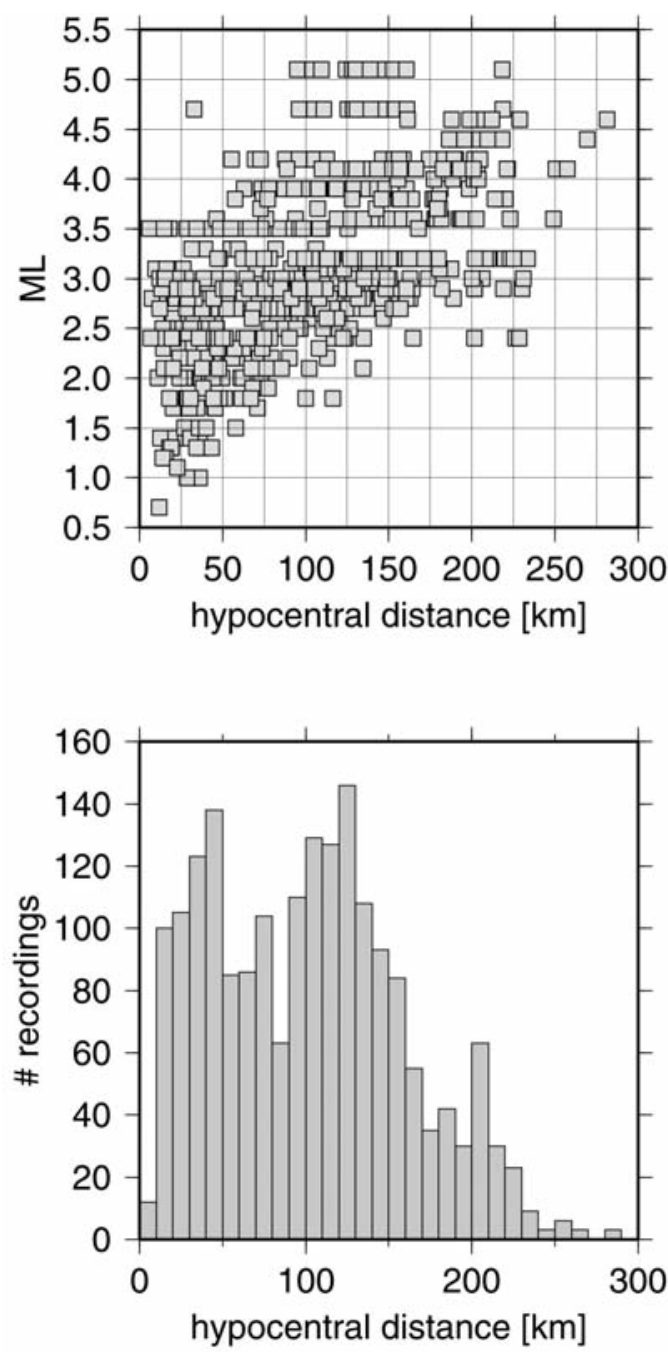

to have the data in real time.

At INGV-MI we have installed the ShakeMap package, developed by the U.S. Geological Survey (USGS) Earthquake Hazards Program [Wald et al. 2006], and we use this tool in agreement with the procedures developed by INGV-CNT for ShakeMap implementation in Italy [Michelini et al. 2008]. A dense and uniform spatial distribution of stations in the field is essential to produce reliable shake maps [Douglas 2007, Moratto et al. 2009], to minimize the uncertainties associated with ground-motion prediction equations [Wald et al. 2008].

To appreciate the role of the RAIS stations in the calculation of the shake maps, an example is given in Figure 8 for the July 14, 2008, $M_{L} 3.5$ earthquake that occurred near Salò. Figure 8 a shows the shake map in terms of the instrumental intensity, as obtained by considering all of the available data (RAIS stations in yellow), while Figure $8 \mathrm{~b}$ shows the PGA residual (in terms of the differences between the values of the ground-motion parameters) obtained by generating the same map considering or not the RAIS stations. Here, the green zone indicates positive residuals
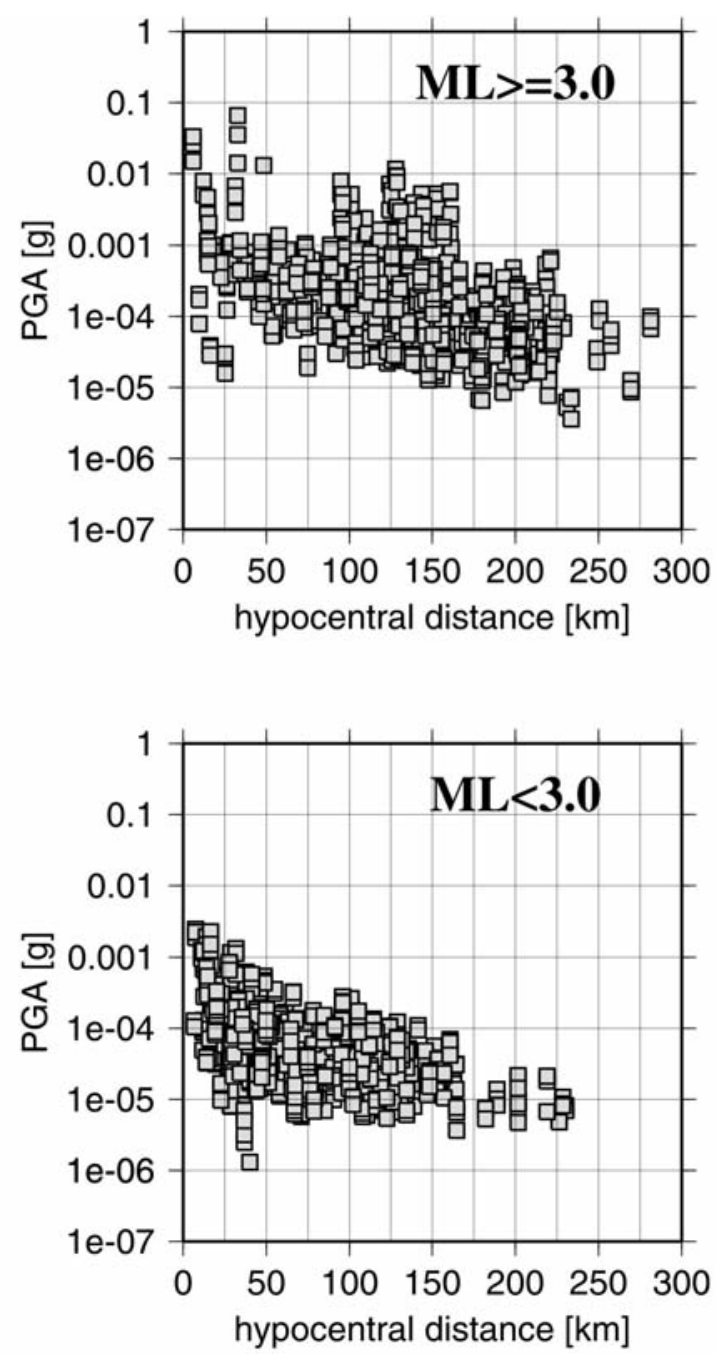

Figure 7. RAIS dataset from June 2006 to June 2010. Left: recordings represented as functions of local magnitude (top) and hypocenter distance (bottom). Right: maximum peak ground acceleration of each record, as $M_{L} \geq 3$ (top) and $M_{L}<3$ (bottom) magnitude classes. 
INGV-MI ShakeMap : NORTHERN ITALY - GARDA MERID.

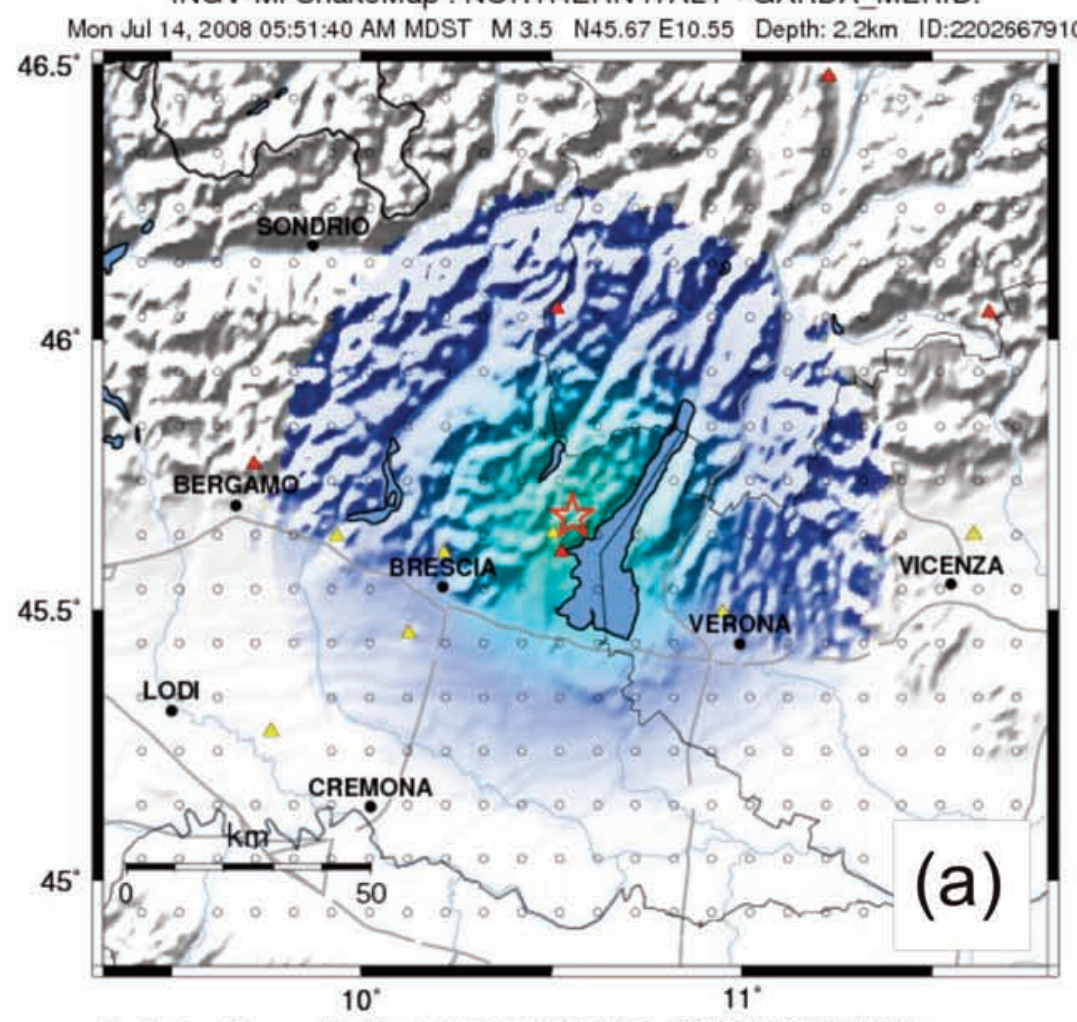

Map Version 1 Processed Wed Sep 8, 2010 06:57:42 PM MDST, - NOT REVIEWED BY HUMAN

\begin{tabular}{|c|c|c|c|c|c|c|c|c|c|}
\hline $\begin{array}{l}\text { PEACEVED D } \\
\text { SHAKIIIS }\end{array}$ & Not felt & Weak & Light & Moderate & Strong & Very strong & Severe & Violent & Extreme \\
\hline $\begin{array}{l}\text { POIEMAIIAL } \\
\text { DAMAEE }\end{array}$ & nome & none & none & Very light & Light & Moderate & Moderate'Heavy & Heavy & Very Heav \\
\hline PEAK ACC.(T/g) & $<.17$ & $.17-1.4$ & $1.4-3.9$ & $3.9-9.2$ & 9.2-18 & 18-34 & $34-65$ & 65.124 & $>124$ \\
\hline PEAK VEL $(\mathrm{cm} / \mathrm{s})$ & $<0.1$ & $0.1-1.1$ & 1.1.3.4 & 3.4-8.1 & 8.1.16 & $16-31$ & 31.60 & 00.116 & $>110$ \\
\hline $\begin{array}{l}\text { INSTRUMENTAL } \\
\text { INTHESTIT }\end{array}$ & I & $\|$ IIII & IV & v & VI & VII & VIII & IX & $x_{+}$ \\
\hline
\end{tabular}

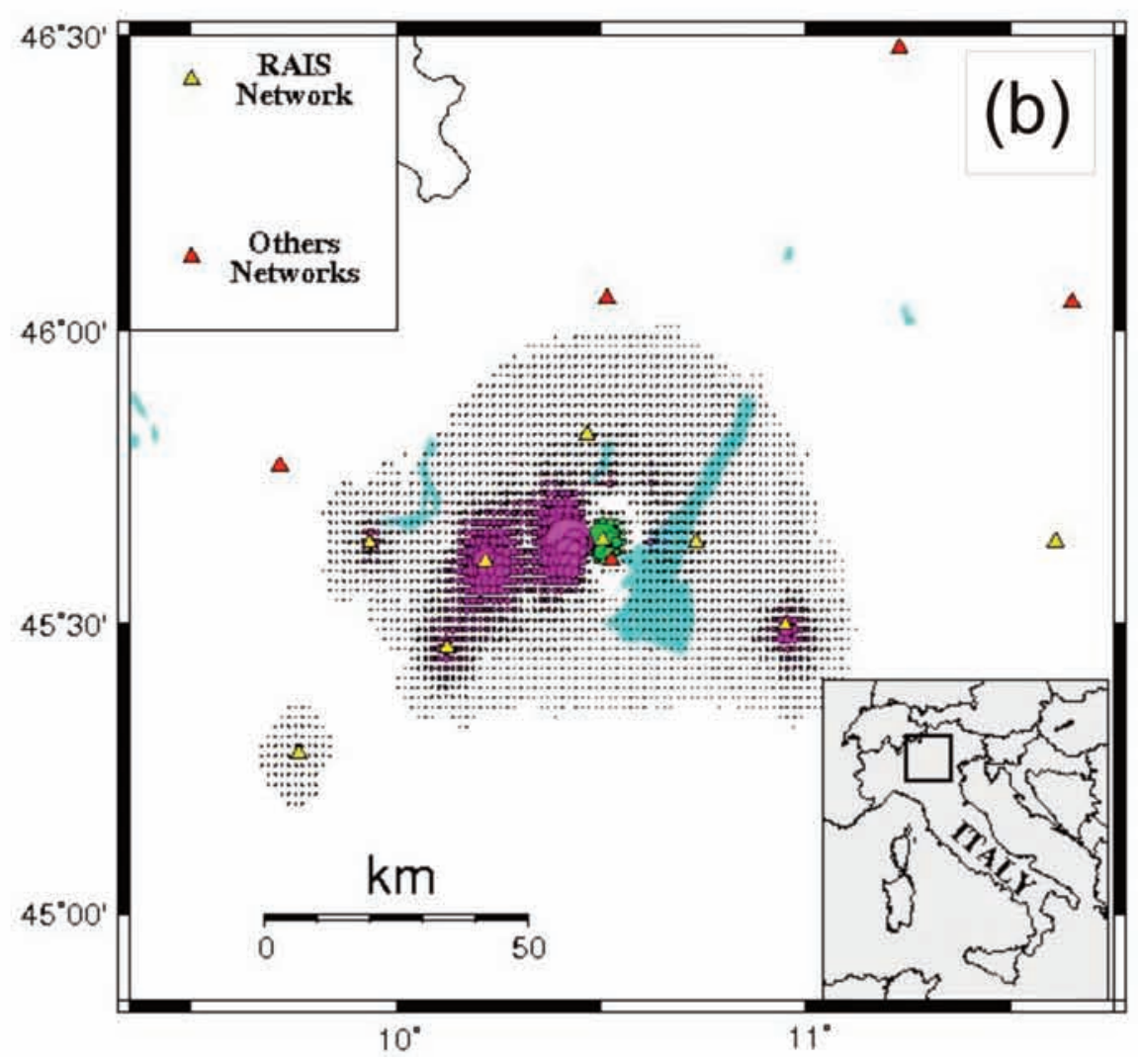

Figure 8. (a) Shake map of July 14, 2008, M 3.5, Garda earthquake for instrumental intensity. Star, epicenter location. (b) PGA residuals obtained with and without considering the RAIS stations. Yellow triangles, RAIS stations; Red triangles, other networks. 
(where the real data recorded by RAIS are higher than the synthetic data calculated by the empirical predictive model). Maximum differences are of the order of $18 \%$. The magenta areas in Figure $8 \mathrm{~b}$ indicate the negative residuals (where the real data recorded by RAIS are lower then the synthetic data calculated by the empirical predictive model). The maximum differences are of the order of $29 \%$.

This result probably arises as the ground-motion prediction equation implemented by the INGV-CNT ShakeMaps package and used for the area under study [Morasca et al. 2006] tends to underestimate the shaking in the near source, and overestimate it in the far field. This demonstrates both the importance of real data availability, to be used as a test, and at the same time the importance of regional variability in the calibration of empirical predictive models.

\section{Conclusions}

Beginning from June 2006, a phase of installation of strong-motion stations in northern Italy started, in the framework of the 2004-2006 INGV-DPC agreement («Stazioni Accelerometriche» project). Over the last four years, subsequent installations have led to the construction of a new strong-motion network in northern Italy, known as RAIS. Over the last two years, through funds provided by the 2007-2009 INGV-DPC agreement (DPC-S3 project), technological improvement of the new network has been possible. At present, 22 strong-motion stations are installed in the central areas of northern Italy, with an average interdistance of about $20 \mathrm{~km}$ (Figure 1). Fourteen of these 22 stations transmit data in real-time mode to the acquisition center in Milan. The recorded data is managed and stored in MiniSEED format by the SeedLink server using a TCP/IP protocol for real-time data communication, under a SeiscomP platform for monitor plotting and disk recording. At present, a phase of upgrading of the last eight dial-up stations (based on GSM technology) is in progress. In the period from June 2006 to June 2010, RAIS recorded 103 events (about 2,000 three-component waveforms; see Figure 2) with $M_{L}$ ranging from 0.7 to 5.1. It is worth noting that the collection of high-quality strong-motion data represents a fundamental tool for earthquake engineering and seismology studies. Over the last few years, the RAIS dataset has represented (as it represents today) a useful source for the calibration of empirical attenuation predictive models computed both at local [Massa et al. 2007, Massa et al. 2008] and at national [Bindi et al. 2009] scales. Moreover, a total of 846 three-component records (in terms of PGA, peak ground velocity and acceleration response spectra, for periods of 0.3 $\mathrm{s}, 1.0 \mathrm{~s}$ and $3.0 \mathrm{~s}$ ) related to 30 events with $\mathrm{M}_{\mathrm{L}} \geq 3.0$ have been sent to the INGV-CNT acquisition center to improve the shake maps (http:/ / earthquake.rm.ingv.it/shakemap/shake/) calculated for the earthquakes that have occurred in northern Italy.
The records from the few stations that were installed inside buildings (e.g. ASO7, BAG8) have allowed us to investigate the soil-structure interactions [Massa et al. 2010]. It is worth noting that high-quality strong-motion records represent the input for each advanced structural analysis that combines ground-motion records with detailed structural models.

All of the metadata related to the events recorded by RAIS (together with information regarding stations and site characterization) are available on the website http:// rais.mi. ingv.it. The waveforms of the events with $M_{L} \geq 2.5$ that were recorded in the period from June 2006 to December 2007 have been included in ITACA (http: / /itaca.mi.ingv.it), in the framework of the 2007-2009 INGV-DPC agreement (S4 project).

Acknowledgments. RAIS arose in the framework of the 2004-2006 INGV-DPC agreement («Stazioni Accelerometriche» project). This study was supported by the 2007-2009 INGV-DPC agreement, in the framework of the DPC-S3 project «Valutazione rapida dei parametri e degli effetti dei forti terremoti in Italia e nel Mediterraneo». Scientific papers funded by the DPC do not represent its official opinion and policies. The authors thank all of the people, both institutional and private citizens, who cooperated in the phases of the installation of RAIS.

\section{References}

Arias, A. (1970). A measure of earthquake intensity, In: Seismic Design of Nuclear Power Plants, edited by R. Hansen, M.I.T. Press, Cambridge.

Augliera, P., E. D'Alema, S. Marzorati, M. Massa, P. De Gori and A. Marchetti (2006). Data set Garda 2004: elaborazione dati, installazione stazioni sismiche (2004 Garda dataset: data processing, installation of seismic stations), Convenzione ProCiv-INGV 2004-2006 - Progetto DPCS3: scenari di scuotimento in aree di interesse prioritario e / o strategico, DPC-S3: Deliverable12, DVD, (in Italian).

Augliera, P., E. D'Alema, S. Marzorati and M. Massa (2009). A strong motion network in northern Italy: detection capabilities and first analyses, B. Earthq. Eng., 8 (5), 10911104; doi: 10.1007 /s10518-009-9165-y.

Bindi, D., L. Luzi, M. Massa and F. Pacor (2009). Horizontal and vertical ground motion prediction equations derived from the Italian Accelerometric Archive (ITACA), B. Earthq. Eng., 8 (5), 1209-1230; doi: 10.1007/s10518-0099130-9.

Bragato, P.L., P. Augliera, E. D'Alema, S. Marzorati, M. Massa and M. Sugan (2009). Effetti di riflessione della Moho in pianura Padana e conseguenze per la stima dello scuotimento nell'Italia settentrionale, XXVIII Convegno Nazionale GNGTS, Trieste 16-19 Novembre 2009, Riassunto Esteso, 364-365 (in Italian).

Brune, J.N. (1970). Tectonic stress and the spectra of seismic shear waves from earthquakes, J. Geophys. Res., 75, 49975009.

CARG Project (2003). Progetto di cartografia geoambientale 
(Regione Lombardia) alla scala 1:25000, versione 1.0, Base cartografica CTR 1:10000, CD-Rom (in Italian).

Castro, R.R., M. Massa, P. Augliera and F. Pacor (2008). Bodywave attenuation in the region of Garda, Italy, Pure Appl. Geophys., 165, 1351-1366.

D'Alema, E. and S. Marzorati (2003). Metodologie per l'installazione e la gestione delle stazioni sismiche Mars88 Modem Control, Rapporti Tecnici INGV, 21 (in Italian).

D'Alema, E. (2007). Stazioni accelerometriche con REFTEK130/modem GSM: note tecniche sui softwares in ambiente Linux per la Rete Accelerometrica dell'Italia Settentrionale. Rapporti Tecnici INGV, 37, (in Italian); available at http:// portale.ingv.it/portale_ingv/produ zione-scientifica/rapporti-tecnici-ingv/archivio/numeripubblicati-2007.

Douglas, J. (2007). Inferred ground motion on Guadaloupe during the 2004 Les Saintes earthquake, B. Earthq. Eng., 5, 363-376.

Gruppo di lavoro CPTI (2004). Catalogo Parametrico dei Terremoti Italiani, versione 2004 (CPTI04), INGV, Bologna; http:/ / emidius.mi.ingv.it/CPTI04/.

Gruppo di Lavoro MPS (2004). Redazione della mappa di pericolosità sismica prevista dall'Ordinanza PCM del 20 marzo 2003. Rapporto Conclusivo per il Dipartimento della Protezione Civile, INGV, Milano-Roma, April 2004 (MPS04), 65 pp. +5 appendices (in Italian).

Hanka, W.A., A. Heinloo and K.-H. Jäckel (2000). Networked seismographs: GEOFON real-time data distribution, ORFEUS Electronic Newsletter, 2, No. 3, http:/ / www. orpheus-eu.org.

Housner, G.W. (1952). Spectrum intensities of strong-motion earthquakes, In: Proceeding of the Symposium on Earthquake and Blast Effects Structures, edited by C.M. Feigen, University of California, Los Angeles, 21-36.

Marzorati, S. and D. Bindi (2006). Ambient noise levels in north-central Italy, Geochem. Geophys. Geosyst., 7, Q09010 doi: 10.1029/2006GC001256.

Massa, M., S. Marzorati, E. D'Alema, D. Di Giacomo and P. Augliera (2007). Site classification assessment for estimating empirical attenuation relationships for north-central Italy earthquake, J. Earthq. Eng., 11, 943-967.

Massa, M., P. Morasca, L. Moratto, S. Marzorati, G. Costa and D. Spallarossa (2008). Empirical ground motion prediction equations for northern Italy using weak and strong motion amplitudes, frequency content and duration parameters, B. Seismol. Soc. Am., 98, 1319-1342.

Massa, M., F. Pacor, L. Luzi, D. Bindi, G. Milana, F. Sabetta, A. Gorini and C. Marcocci (2009). The Italian Accelerometric Archive (ITACA): processing of strong motion data, B. Earthq. Eng., doi: 10.1007/s10518-009-9152-3.

Massa, M., S. Marzorati, C. Ladina and S. Lovati (2010). Urban seismic stations: soil-structure interaction assessment by spectral ration analyses, B. Earthq. Eng., 8, 723-738.

McNamara, D.E. and R.P. Buland (2004). Ambient noise levels in continental United States, B. Seismol. Soc. Am., 94, 1517-1527.

Michelini, A., L. Faenza, V. Lauciani and L. Malagnini (2008). ShakeMap implementation in Italy, Seismol. Res. Lett., 79, 688-697.

Morasca, P., L. Malagnini, A. Akinci, D. Spallarossa, and R.B. Herrmann (2006). Ground-motion scaling in the western Alps, J. Seismol., 10, 315-333.

Moratto, L., G. Costa and P. Suhadolc (2009). Real-time generation of ShakeMaps in the southeastern Alps, B. Seismol. Soc. Am., 4, 2489-2501.

Nakamura, Y. (1989). A method for dynamic characteristics estimation of subsurface using microtremor on the ground surface, Railway Technical Research Institute (Tokyo, Japan), Quarterly Reports, 30 (1), 25-33.

NTC (2008). Nuove Norme Tecniche per le Costruzioni. Part 3: Categorie di sottosuolo e condizioni topografiche, Gazzetta Ufficiale, 29, 4 febbraio 2008.

Peterson, J. (1993). Observation and modeling of background seismic noise, U.S. Geological Survey Open File Report 93-322, Albuquerque, New Mexico, 95 pp.

Rao, S., L. Salvaterra and C. Acerra (2010). Software per l'installazione e la configurazione della stazione sismica GAIA2, Rapporti Tecnici INGV, 130, 52 pp. (in Italian).

Società Geologica Italiana (1984). Carta geologica d'Italia 1:100000, Base cartografica IGM 1:25000.

Wald, D.J., C.B. Worden, V. Quitoriano and K.L. Pankow (2006). ShakeMap Manual, Technical Manual, Users Guide, and Software Guide; http:// pubs.usgs.gov/tm/ 2005/12A01/pdf/508TM12-A1.pdf.

Wald, D.J., V. Quitoriano, T.H. Heaton and H. Kanamori (2008). Quantifying and Qualifying USGS ShakeMap Uncertainty, U.S. Geological Survey Open File Report 2008-1238.

\footnotetext{
${ }^{\star}$ Corresponding author: Paolo Augliera,

Istituto Nazionale di Geofisica e Vulcanologia, Sezione Milano-Pavia, Milan, Italy; e-mail: paolo.augliera@mi.ingv.it.

C 2011 by the Istituto Nazionale di Geofisica e Vulcanologia. All rights reserved.
} 